\title{
Transcatheter Closure of Atrial Septal Defects in a Center With Limited Resources: Outcomes and Short Term Follow-Up
}

\author{
Sukman T. Putra,, ${ }^{1, *}$ Mulyadi M. Djer, ${ }^{1}$ Nikmah S. Idris, ${ }^{1}$ Hasri Samion, ${ }^{2}$ and Sudigdo \\ Sastroasmoro ${ }^{1}$ \\ ${ }^{1}$ Division of Cardiology, Department of Pediatrics and Child Helath, Integrated Cardiovascular Center, Dr. Cipto Mangunkusumo Hospital, University of Indonesia, Jakarta, \\ Indonesia \\ ${ }^{2}$ Department of Pediatric Cardiology, National Heart Institute, Kuala Lumpur, Malaysia \\ ${ }^{*}$ Corresponding author: Sukman T. Putra, Department of Pediatrics and Child Health, Integrated Cardiovascular Center, Dr. Cipto Mangunkusumo Hospital, University of Indonesia, \\ P. O. Box: 10430, Jakarta, Indonesia. Tel: +62-213907742; +62-811864703, Fax: +62-3907743, E-mail: sukmanputra@yahoo.com
}

Received 2015 August 23; Accepted 2015 September 20

\begin{abstract}
Background: Transcatheter closure of atrial septal defects (ASD) has been accepted world-wide as an alternative to surgical closure with excellent results. This interventional, non-surgical technique plays an important role in the treatment of ASD mostly in the developing world where resources are limited.

Objectives: To report the outcomes and short term follow-up of transcatheter closure of ASD over a 12-year period at our institution with limited resources.

Patients and Methods: This retrospective study included all patients with the diagnosis of secundum ASD and significant shunting (Qp/Qs > 1.5:1) as well as dilated right atrium and right ventricle who had transcatheter closure at Integrated Cardiovascular Center (PJT), Dr. Cipto Mangunkusumo Hospital between October 2002 and October 2014. One hundred fifty-two patients enrolled in this study were candidates for device closure. Right and left heart cardiac catheterization was performed before the procedure. All patients underwent physical examination, ECG, chest X-ray and transthoracal echocardiography (TTE) prior to device implantation.

Results: A total of 152 patients with significant ASD underwent device implantation. Subjects' age ranged from 0.63 to 69.6 years, with median 9.36 years and mean 16.30 years. They consisted of $33(21.7 \%)$ males and 119 (78.3\%) females, with mean body weight of $29.9 \mathrm{~kg}$ (range 8 to $75 ;$ SD 18.2). The device was successfully implanted in 150 patients where the majority of cases received the Amplatzer septal occluder $(147 / 150 ; 98 \%)$ and the others received the Heart Lifetech ASD occluder $(3 / 150,2 \%)$, whereas two other cases were not suitable for device closure and we decided for surgical closure. The mean ASD size was 19.75 (range 14 - 25) mm. During the procedure, 5 (4.9\%) patients had bradycardia and 3 (2.9\%) patients had supraventricular tachycardia (SVT), all of which resolved.

Conclusions: In our center with limited facilities and manpower, transcatheter closure of atrial septal defect was effective and safe as an alternative treatment to surgery. The outcome and short-term follow-up revealed excellent results, but long-term follow-up is needed.
\end{abstract}

Keywords: Atrial Septal Defect, Transcatheter Closure, Limited Resources, Surgical Closure

\section{Background}

Atrial septal defect (ASD) is one of the most common cardiac congenital defects, accounting for 5 to $10 \%$ of all cases of congenital heart disease (CHD). From an epidemiological viewpoint, this type of CHD predominantly occurs in females, at a female: male ratio of 1.5 - 3.5:1. For many decades, surgical intervention for ASD has been accepted as the standard treatment with excellent outcomes. However, although surgical treatment is safe, it is associated with morbidity, discomfort and thoracotomy scars (1). In developing countries such as Indonesia, obstacles to surgical procedures include the limited number of ICU beds, cardiac surgeons, intensivists, and other resources. Therefore, current advances in non-surgical treatment of ASD with devices has become the treatment of option in a country with limited resources (2).
The first transcatheter occlusion of ASD was described by King and colleagues in 1976 (3). Afterwards, many reported satisfactory results of transcatheter closure for ASD using several types of devices. The Amplatzer septal occluder (ASO) was first introduced into clinical practice by Masura and colleagues in 1997 (4), followed by a publication from Bialkowski et al. in 2003 (5). Behjati et al. (2011) (6), from Iran reported good results and effective procedure of transcatheter closure of ASD using Amplatzer Septal Occluder. Since transcatheter closure of congenital heart disease, in particular atrial septal defects (ASD) has the advantages of short hospital stay, less discomfort for patients, not requiring ICU beds, and no incisional scar, it has been accepted worldwide as an alternative to surgery.

Copyright (C) 2015, Growth \& Development Research Center. This is an open-access article distributed under the terms of the Creative Commons Attribution-NonCommercial 4.0 International License (http://creativecommons.org/licenses/by-nc/4.0/) which permits copy and redistribute the material just in noncommercial usages, provided the original work is properly cited. 
Figure 1. Diagram of the Steps of Procedures of Implantation of ASD Devices From Advancing to Left Atrium and Then Releasing After Device is Stable.

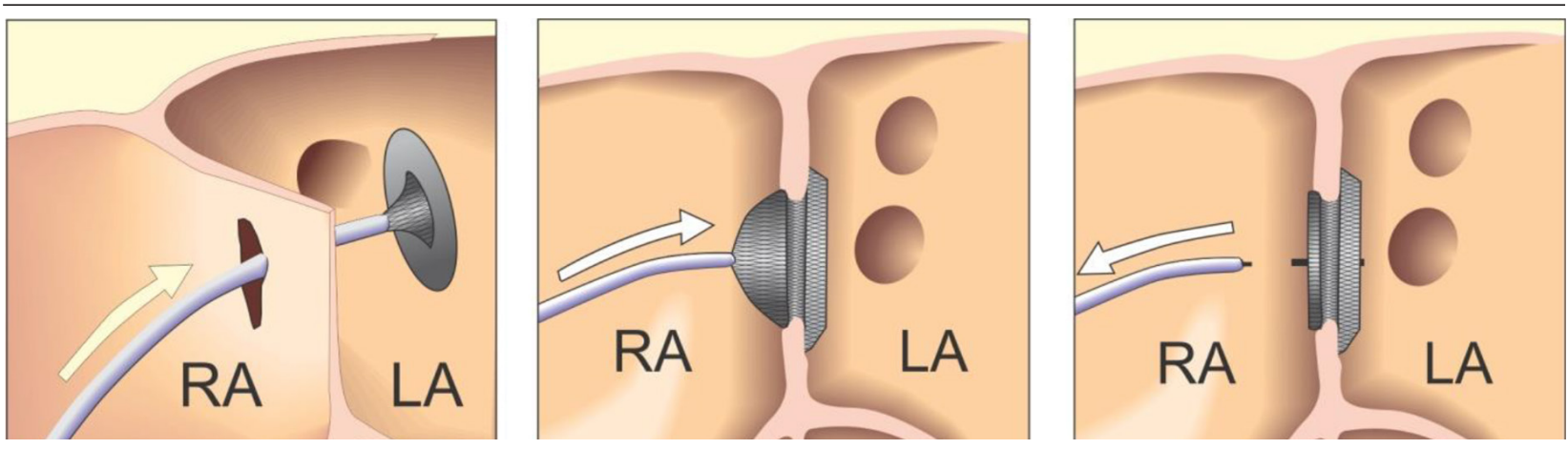

RA, right atrium; LA, left atrium.

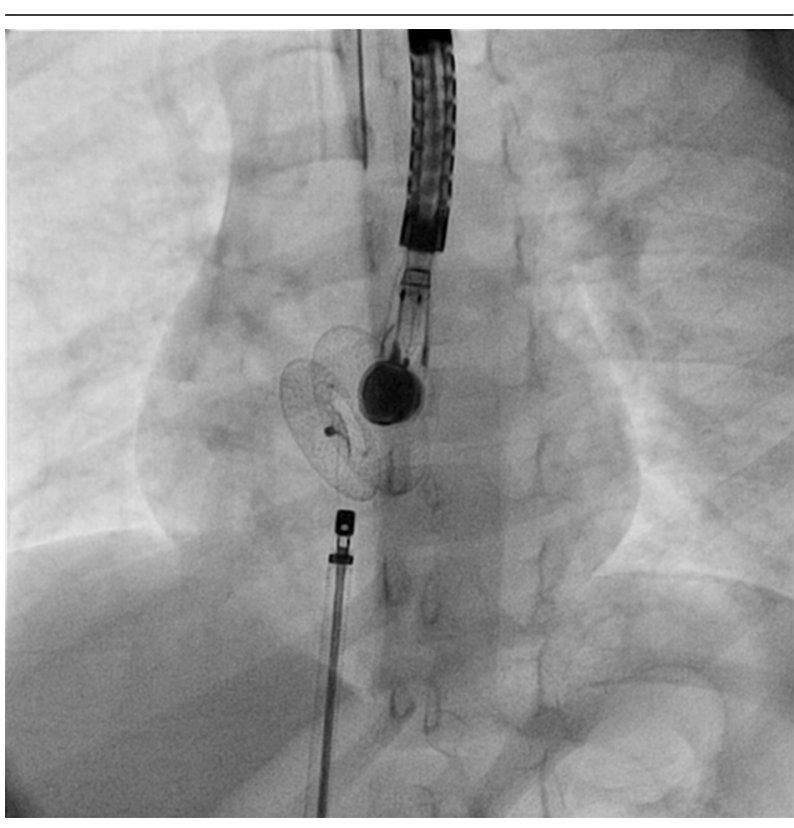

Figure 2. Implantating ASD Device Occluder Guided by Transesophageal Echocardiography.

\section{Objectives}

We report this retrospective review from our experience in a single center with limited resources concerning the transcatheter closure of ASD as an alternative to surgery, with the majority of procedures done in children.

\section{Patients and Methods}

One hundred fifty patients with significant ASD who underwent transcatheter closure between October 2002 and October 2014 were enrolled in the study. This retrospective study included all patients with a diagnosis of secundum ASD and significant shunting (Qp/Qs > 1.5:1), as well as dilated right atrium and right ventricle.

\subsection{Devices}

The majority of patients (147/150) received the Amplatzer septal occluder, a self-centering and self-occlusion device made from nitinol wire mesh. The device comprises a left atrial retension disc, self-centering stent and right atrial disc. Similar devices of Lifetech were implanted in 3 patients. During the procedure the devices were attached to the delivery cable with a screw at the end of the device.

\subsection{Procedures}

Right and left heart cardiac catheterization was performed for hemodynamical study under general anesthesia. Before the procedure, all patients underwent physical examination, ECG, chest X-ray, and complete blood examination. Transthoracal echocardiography was also performed to confirm the diagnosis and assess the suitability of the defect closure. During the procedure transesophageal echocardiography (TEE) was performed. Heparin (100 IU $/ \mathrm{kg}$ ) was administered to prevent clotting and embolism.to visualize the atrial septum and the defect, angiocardiography was performed in the right upper pulmonary vein in the 4-chamber view. The stretched diameter was measured for balloon sizing in the majority of cases. Devices were selected on the basis of the stretched diameter or $1 \mathrm{~mm}$ larger. The device was advanced via the long sheath to the left atrium by pushing the delivery cable. The device was then deployed in the left atrium under fluoroscopic and TEE guidance (Figures 1 and 2). Intravenous (IV) cefazolin ( $1 \mathrm{~g}$ ) was given to prevent bacterial endocarditis and aspirin was prescribed at a dose of $5 \mathrm{mg} / \mathrm{kg}$ daily for 3 months to avoid thromboembolic events. Cefazolin was given 30 minutes prior to procedure and followed by $1 \mathrm{~g}$ IV every 8 hours for an additional 2 doses. Follow-up studies were done on the 1st day, 1 month, and 6 months after the procedure, and included transthoracal echocardiography, chest X-ray, and electrocardiography.

\section{Results}

In 150 (99.1\%) out of 152 patients with significant ASD, atrial septal devices consisting of 147 Amplatzer septal occluders (ASO) and 3 Heart Lifetech devices were successfully implanted. Subjects' age ranged from 0.63 to 
Putra ST et al.

69.6 (median 9.36; mean 16.30) years and consisted of 33 (21.7\%) males and 119 (78.3\%) females. Their mean body weight was 29.9 (range 8-75; SD 18.2) kg. The mean ASD size measured by balloon sizing was 19.7 (range 4 -125) $\mathrm{mm}$.

The mean procedure time was 114.04 (range 43 - 274; SD 41.99) minutes. The mean flow ratio was 3.08 (1.7 - 27; SD 3.22). The mean fluoroscopy time was 32.81 (1.5 - 100; SD 17.22) minutes. The mean ASD size was 19.71 (range 14 - 25) $\mathrm{mm}$ (Table 1). During the procedures, 5 (4.9\%) patients had bradycardia and 3 (2.9\%) supraventricular tachycardia (SVT), all of which resolved medically (Table 2 ).

Immediately after device implantation, complete closure was observed in 135 (90.0\%) patients, trivial/smoky residual shunt was detected in 15 (10.0\%) patients, and a persistent residual shunt was observed in 1 (0.6\%) patient. In 2 patients, the device migrated, requiring surgical intervention. The overall success rate was 148/150 (98.6\%). At the 6-month follow-up visit, all (100\%) patients had complete closure, which was confirmed by TTE.

\begin{tabular}{lc}
\hline \multicolumn{2}{l}{ Table 1. Patients' Characteristics and Procedures ${ }^{\mathrm{a}}$} \\
\hline \multicolumn{1}{l}{ Variables } & \multicolumn{1}{c}{ Values } \\
\hline Age, $\mathbf{y}$ & $9.36(0.63-69.56)$ \\
Gender & $119(78.3)$ \\
\hline \multicolumn{1}{l}{ Female } & $33(21.7)$ \\
\hline Male & $24.00(8-75)$ \\
Weight, Kg & $2.2(1.7-2.7)$ \\
Qp/Qs & $18.00(4-125)$ \\
Size of ASD, mm & $115(43-274)$ \\
\hline Procedure time, min & $29.3(1.5-100)$ \\
\hline Fluoroscopy time, min & $21(3-74)$ \\
\hline Mean PA pressure, mmHg
\end{tabular}

${ }^{\mathrm{a}}$ Values are presented as Median (range) or No. (\%).

Table 2. Complications from ASD Device Closure ${ }^{a, b}$

\begin{tabular}{lc}
\hline Complications & No. of Cases \\
\hline Major complications & \\
\hline Embolization (requiring surgery) & $2(1.3)$ \\
\hline Minor complications & \\
\hline Supraventricular tachycardia & $3(2.9)$ \\
\hline Bradycardia & $5(4.9)$ \\
\hline Anemia (requiring transfusion) & $1(1.0)$ \\
\hline
\end{tabular}

$\mathrm{a}_{\mathrm{N}=150 \text {. }}$

$\mathrm{b}_{\text {Values are presented as No. (\%). }}$

\section{Discussion}

Interventional treatment or non-surgical intervention for atrial septal defect (ASD) has been accepted worldwide as an alternative to surgical closure in developed countries as well as in developing countries. It has been reported in many centers in the world with excellent results $(7,8)$. This procedure has been accepted as an alternative treatment to surgery. Most pediatric cardiac centers use transesophageal echocardiography (TEE) for guiding the implantation of the devices, but the high success rate of septal device implantation using transthoracal echocardiography guiding was reported by Zanjani et al. (9). The major advantages of transcatheter closure for ASD are the short hospital stay as well as avoiding thoracotomy, cardiopulmonary bypass, intensive care and surgical scars. In developing countries with limited resources and health care funding, non-surgical treatment for congenital heart disease, in particular atrial septal defect, needs to be cost-effective and safe. This study reports our experience in a single center with limited resources. We have one cathlab with single-plane, a combined adult and pediatric ICU, and a limited number of intensivists and cardiac nurses.

Indonesia belongs to one of the middle-income countries in the world based on the classification of World Bank, where the gross national income per capita in 2013 was USD 9.561. Definition of developing coutries and limited resources is very subjective and there are no clear cut criteria (10). In general cardiac centers in developing countries have limitation of infrastructures and well trained man power. Indonesia is the biggest country in the South East Asia region in terms of population and geographic area. It has 240 million inhabitants and around 70 million children under the age of 18 years. The country has more than 17.000 islands, 6000 of which are inhabited. This causes a big problem to refer the patients from remote places to cardiac centers or referral hospitals. With the birth rate of $2.0 \%$ and assuming that the incidence of CHD of 8 - 10 per 1000 live births, around 45.000 babies with CHD are born every year. Unfortunately there are only 2 centers that have comprehensive pediatric cardiac care including cardiac surgery, intervention facilities, and intensive care for infants and neonates. Both centers are located in the capital city of Jakarta, i.e., National Cardiac Center Harapan Kita and Integrated Cardiovascular Center at Dr Cipto Mangunkusumo Hospital. There are 8 other centers in the country with very low numbers of cardiac surgeries or interventional procedures. All of these centers combine all facilities for children and adults. For the whole country there are only 45 pediatric cardiologists, 4 dedicated pediatric cardiac surgeons, and only 4 pediatric cardiac intensivists. The number of manpower is very far from ideal number recommended by American College of Cardiology (ACC). This demands that for every 5 million people there should be at least one pediatric cardiac center available (11). The ideal surgical procedures performed in every center should be at least 250 procedures. It means that for 240 million population Indonesia should have at least 48 cardiac centers.

The coverage of surgery for all over the country is only about $11.6 \%$. The figures of the pediatric cardiac care and the manpower in Indonesia is shown in Table 3. 
Putra ST et al.

Table 3. Existing Pediatric Cardiac Facilities and Coverage in Indonesia (2014) (12) $)^{\mathrm{a}, \mathrm{b}}$

\begin{tabular}{|c|c|}
\hline Heart Center & Values \\
\hline \multicolumn{2}{|l|}{ Number of pediatric cardiac surgeries per year } \\
\hline National Cardiac Center (Harapan Kita), Jakarta & $900(63.4)$ \\
\hline Dr Cipto Mangunkusumo Hospital (PJT RSCM), Jakarta & $434(30.6)$ \\
\hline Other centers (8) & $85(6)$ \\
\hline Total & 1419 cases \\
\hline \multicolumn{2}{|l|}{ Pediatric cardiac interventions per year } \\
\hline National Cardiac Center (Harapan Kita), Jakarta & $163(45.7)$ \\
\hline Dr Cipto Mangunkusumo Hospital (PJT RSCM), Jakarta & $120(33.7)$ \\
\hline Other centers (8) & $48(13.25)$ \\
\hline Total & 331 cases \\
\hline Total Surgery + Intervention & 1740 cases \\
\hline Total coverage for expected 5000 cases per year & $1740 / 15.000=11.6$ \\
\hline \multicolumn{2}{|c|}{ 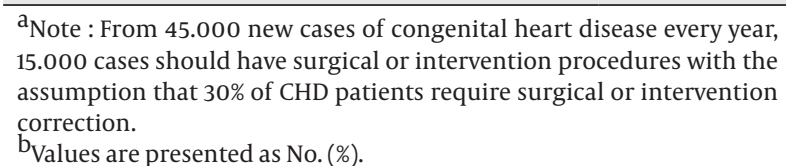 } \\
\hline
\end{tabular}

The developing country Indonesia is facing many problems which cause very limited development in pediatric cardiac care. The problems include: (a) lack of access to pediatric cardiac center due to financial and geographic situation, (b) shortage of well trained professional specialists for pediatric cardiac care, (c) shortage of health care workers including cardiac technicians and nurses, (d) lack of facilities for pediatric cardiac care, (e) competing priorities by the government in the national health care system. With regard to particular conditions with limited ICU beds and pediatric cardiac surgeons, the non-surgical treatment of CHD becomes an alternative to surgery. ASD is one of the types of CHD that could be corrected by transcatheter closure cost-effecticvely and safely. This study reports experience of a single center with limited resources and one old cathlab with single-plane, combined ICU for adults and children, in addition to limited number of intensivists and cardiac nurses. Currently we have only one cardiac surgeon dedicated to pediatric patients in our institution. In the beginning of learning curve, we have been supported by some of our colleagues, pediatric cardiologists from Malaysia.

A comparison of surgical and transcatheter closure results revealed some advantages of the latter in terms of fewer complications (7.2\% non-surgical vs. $24.0 \%$ surgical) and shorter hospital stay in the transcatheter closure group $(1.0+0.3$ days vs. $3.4+1.2$ days in the surgical group) (13). Chessa et al. reported on a large series of transcatheter closure of 417 patients with secundum ASD using Amplatzer and CardioSEAL/StarFlex devices showing complications in 36/417 (8.65\%) cases. the most common complication being device embolization/malposition in $3.5 \%$ of the cases (14) Arrythmia was another common complication that occured in $11 / 417$ (2.6\%) cases, 6 of which developed atrial fibrilation that required cardioversion. The report by Spies et al. revealed that 6/170 (3.5\%) patients with transcatheter closure of ASD had atrial fibrillation (15).

Cardiac erosion by Amplatzer device was an important complication that one should be aware of. It was reported by Amin et al. (16).

With a success rate of $>98 \%$, our center has performed an effective procedure for ASD closure using devices. However, our cases were not free from complications. Three $(2.8 \%)$ patients had supraventricular tachycardia and $5(4.9 \%)$ had transient bradycardia. These complications completely recovered medically and spontaneously. Thus, a total of 8 (7.7\%) patients had complications, similar to a study by Du et al. (13). In fact, complications from transcatheter closure of ASD, in general, are very low (17). Another advantage of transcatheter closure of ASD using a device is the retrievability during device deployment which may prevent embolization or malposition. Two (1.4\%) of our patients experienced embolizations that required surgical intervention. This condition may have been due to insufficient rims.

There were some limtations in our study. This study was a retrospective study design with a small number of cases who had transcatheter closure of secundum ASD and there was no comparation to the results of a surgical closure group. To see the complications of device implantation ideally requires a long period of time, this was in our cases relatively short.

In the past, residual shunts were more frequently reported with transcatheter closure than with surgical closure, due to different types of devices implanted. Rao et al. (18) reported the residual shunt of $45 \%$ by using "bootoned" devices. However, nowadays the incidence of residual shunts is very low using the Amplatzer septal occluder. Kazmi et al. (19) reported that only 3 of 202 patients had small residual leaks immediately after procedures. In our study, only 1 of 150 (0.6\%) patients had a small residual shunt which was completely closed at the 6 month follow-up visit.

We conclude that transcatheter closure of atrial septal defects in children and adolescents was effective and safe. It is a good alternative to surgery in the centers with limited resources in developing countries, as the outcome has been excellent and it has even some advantages over surgical closure.

\section{References}

1. Pastorek JS, Allen HD, Davis JT. Current outcomes of surgical closure of secundum atrial septal defect. Am J Cardiol. 1994;74(1):757. [PubMed: 8017313]

2. Putra ST, Djer MM, Idris NS, editors. Transcatheter closure of ASD in limited resources pediatric heart center: the problems and outcomes.; Proceedings in The Congenital CardiacConference HCMC.; 2012

3. King TD, Mills NL. Nonoperative closure of atrial septal defects. Surgery. 1974;75(3):383-8. [PubMed: 4811334] 
4. Masura J, Gavora P, Formanek A, Hijazi ZM. Transcatheter closure of secundum atrial septal defects using the new self-centering amplatzer septal occluder: initial human experience. Cathet Cardiovasc Diagn. 1997;42(4):388-93. [PubMed: 9408617]

5. Bialkowski J, Kusa J, Szkutnik M, Kalarus Z, Banaszak P, Bermudez-Canete R, et al. [Percutaneous catheter closure of atrial septal defect. Short-term and mid-term results]. Rev Esp Cardiol. 2003;56(4):383-8. [PubMed:12689573]

6. Behjati M, Mirhosseini SJ, Hosseini SH, Rajaei S. Transcatheter Closure of Atrial Septal Defect with Amplatzer Device in Children and Adolescents: Short and Midterm results; an Iranian Experience. Iran J Pediatr. 2011;21(2):166-72. [PubMed: 23056783]

7. Fischer G, Stieh J, Uebing A, Hoffmann U, Morf G, Kramer HH. Experience with transcatheter closure of secundum atrial septal defects using the Amplatzer septal occluder: a single centre study in 236 consecutive patients. Heart. 2003;89(2):199-204. [PubMed: 12527678]

8. Butera G, De Rosa G, Chessa M, Rosti L, Negura DG, Luciane P, et al. Transcatheter closure of atrial septal defect in young children: results and follow-up. J Am Coll Cardiol. 2003;42(2):241-5. [PubMed: 12875758]

9. Zanjani KS, Zeinaloo A, Malekan-Rad E, Kiani A, Bagheri MM. Transcatheter Atrial Septal Defect Closure under Transthorasic Echocardiography in Children. Iran J Pediatr. 2011;21(4):473-8. [PubMed: 23056834]

10. Kumar RK. Delivering pediatric cardiac care with limited resources. Ann Pediatr Cardiol. 2014;7(3):163-6. doi: 10.4103/09742069.140825. [PubMed: 25298689]

11. Rahajoe AU. Management of patients with congenitally malformed hearts in Indonesia. Cardiol Young. 2007;17(6):584-8. doi: 10.1017/S1047951107001588. [PubMed:17953784]

12. Putra ST, editor. Interventional cathetetrization treatment of congenital heart disease in children. Procceding of 10th Japan-
China-Korea Pediatric Heart Forum.; 2014; Okayama, Japan.

13. Du ZD, Hijazi ZM, Kleinman CS, Silverman NH, Larntz K, Amplatzer I. Comparison between transcatheter and surgical closure of secundum atrial septal defect in children and adults: results of a multicenter nonrandomized trial. J Am Coll Cardiol. 2002;39(11):1836-44. [PubMed:12039500]

14. Chessa M, Carminati M, Butera G, Bini RM, Drago M, Rosti L, et al. Early and late complications associated with transcatheter occlusion of secundum atrial septal defect. J Am Coll Cardiol. 2002;39(6):1061-5. [PubMed:11897451]

15. Spies C, Timmermanns I, Schrader R. Transcatheter closure of secundum atrial septal defects in adults with the Amplatzer septal occluder: intermediate and long-term results. Clin Res Cardiol. 2007;96(6):340-6. doi: 10.1007/s00392-007-0502-3. [PubMed: 17323009]

16. Amin Z, Hijazi ZM, Bass JL, Cheatham JP, Hellenbrand WE, Kleinman CS. Erosion of Amplatzer septal occluder device after closure of secundum atrial septal defects: review of registry of complications and recommendations to minimize future risk. Catheter Cardiovasc Interv. 2004;63(4):496-502. doi: 10.1002/ ccd.20211. [PubMed: 15558755]

17. Huang TC, Hsieh KS, Lin CC, Lee CL. Clinical results of percutaneous closure of large secundum atrial septal defects in children using the Amplatzer septal occluder. Heart Vessels. 2008;23(3):18792. doi:10.1007/s00380-007-1028-3. [PubMed: 18484162]

18. Rao PS, Sideris EB, Hausdorf G, Rey C, Lloyd TR, Beekman RH, et al. International experience with secundum atrial septal defect occlusion by the buttoned device. Am Heart J.1994;128(5):1022-35. [PubMed: 7942465]

19. Kazmi T, Sadiq M, Asif ur R, Hyder N, Latif F. Intermediate and long-term outcome of patients after device closure of ASD with special reference to complications. J Ayub Med Coll Abbottabad. 2009;21(3):117-21. [PubMed: 20929028] 